1 Universidade Federal de São Paulo (Unifesp) - São Paulo (SP), Brasil. carol.chaccur@gmail.com

2 Universidade Federal de São Paulo (Unifesp) - São Paulo (SP), Brasil.

luizcecilio60@gmail.com

3 Instituto Universitário de Lisboa (ISCTE) - Lisboa,

Portugal.

tiago.correi@@iscte.pt

\section{Os médicos e a racionalização das práticas hospitalares: novos limites para a liberdade profissional?}

\author{
Physicians and the rationalization of hospital practices: new limits for \\ professional freedom?
}

Carolina Chaccur Abou Jamra', Luiz Carlos de Oliveira Cecilio², Tiago Correia³
RESUMO Os hospitais brasileiros experimentam um marcado processo de racionalização de suas práticas na busca de maiores eficiência e eficácia organizacional. Considerando a existência de um sistema dual de autoridades composto pelos poderes médico e administrativo, este estudo visa a compreender como os médicos vivenciam e dão sentido às políticas racionalizadoras da gestão hospitalar implementadas pela direção de um hospital da Secretaria de Saúde do Estado de São Paulo. Utilizando-se de análise documental e entrevistas, o estudo evidenciou um aparente paradoxo entre os avanços dos mecanismos de controle organizacional sobre o trabalho médico e a percepção de tais avanços pelos médicos.

PALAVRAS-CHAVE Administração hospitalar; Acreditação; Autonomia profissional; Relações hospital-médico; Corpo clínico hospitalar.

ABSTRACT Brazilian hospitals experience a remarkable rationalization process of its practices in the quest for greater efficiency and organizational effectiveness. Considering the existence of a dual system of authorities composed by both medical and administrative powers, the present study aims to understand how medical experience and assign meaning to the rationalizing policies of the hospital management implemented by one hospital management board of the State Health Department of São Paulo. By documentary analysis and interviews, this research showed an apparent paradox between the advances of the organizational mechanisms of control over medical work and the perception of such advancements by the physicians.

KEYWORDS Hospital administration; Accreditation; Professional autonomy; Hospital-physician relations; Medical staff, hospital. 


\section{Introdução}

Os hospitais modernos vêm experimentando um marcado processo de racionalização de suas práticas a partir de estratégias que visam a disciplinar, regulamentar e controlar a vida organizacional, introduzindo elementos de previsibilidade, redução da variabilidade e controle do trabalho, incluindo aí a prática dos profissionais médicos, interesse central deste estudo. Tal 'racionalização' deve ser entendida como parte de uma lógica eficientista que pensa o hospital como empresa, com crescentes custos operacionais em virtude do impacto do sistema técnico na produção dos cuidados, que atua em um mercado de saúde cada vez mais competitivo e, portanto, devendo ser administrado a partir de estratégias assentadas sobre princípios racionais, quais sejam: técnicos, objetivos e eficientes (CARAPINHEIRO, 1998; CORREIA, 2012). Essa tendência também pode ser observada no campo público governamental, o que tem sido denominado gerencialismo por alguns autores (PAULA, 2005; VIEIRA; CARVALHO, 1999).

Para Carapinheiro (1998), haveria no hospital uma estrutura dual de autoridade: o poder médico e o poder administrativo. A introdução de uma lógica crescentemente racionalizadora por parte da administração hospitalar supostamente haveria de resultar num embate com o poder de decisão do corpo médico, que, por sua vez, ativaria estratégias de conservação da autonomia dos serviços, que visariam, como resultado final, à manutenção do poder médico na instituição.

Nesse modelo de racionalidade médica, pensado a partir do conceito original de profissionalismo de Freidson (2001), é o ideal de uma prática liberal o que os médicos procuram preservar na organização hospitalar. Sua autonomia pode ser caracterizada, entre outras coisas, pela manutenção do direito de selecionar clientela de acordo com os 'casos clínicos interessantes', de reservar leitos, definir horários de trabalho, dedicar-se mais ou menos à assistência direta aos pacientes etc. e, assim, contrapor-se à autoridade administrativa. A manutenção de tal autonomia na sua forma mais ou menos ideal vai depender das diferentes acumulações de poderes na instituição e difere, inclusive, entre os próprios médicos (CARAPINHEIRO, 1998).

Para Schraiber $(1993,2008)$, com a transição da medicina liberal para a medicina tecnológica, período compreendido entre as décadas de 1940 e 1960, os médicos, tensionados pela crescente especialização da medicina com incorporação tecnológica, pela divisão técnica do trabalho, pela institucionalização e pelo assalariamento, desenvolveram novos arranjos tecnológicos que resultaram em grandes perdas mercantis e produtivas da autonomia médica liberal, preservando, contudo, mas com características diferentes, sua autonomia técnica. Para a autora, é na dimensão técnica da autonomia que o médico, através de um discurso geral, impreciso e universalizante, reconstitui seu ideal como representação, "um símbolo mítico do ideal de prática" (SCHRAIBER, 1993, P. 214).

Apesar da dicotomia originalmente descrita entre a autonomia médica e os imperativos burocráticos das organizações hospitalares, têm emergido na literatura europeia novas evidências quanto a não linearidade dessa oposição. Conceitos como 'hybrid profissionalism' (NOORDEGRAAF, 2007), 'organized profissionalism' (NOORDEGRAAF, 2011) ou 'balkanized professionalism' (CORREIA, 2014) são alguns exemplos disso.

Levando-se em consideração tal debate sobre autonomia médica, este estudo teve como objetivo analisar como os médicos vivenciam e dão sentido às políticas racionalizadoras da gestão hospitalar implementadas pela direção de um hospital da Secretaria de Saúde do Estado de São Paulo gerenciado nos moldes de uma organização social. Tinha-se como pressupostos iniciais da investigação que: a) as políticas de qualificação da gestão atualmente adotadas pelos hospitais, componente central das estratégias de racionalização das práticas médico-hospitalares, contêm 
elementos que podem, potencialmente, restringir a autonomia do trabalho médico ao buscar ajustá-lo à racionalidade proposta pela direção (previsibilidade e homogeneização de condutas e monitoramento permanente referenciado a parâmetros de produção e qualidade); b) tais políticas, por significarem regulamentação e normalização de fluxos, rotinas e processos de trabalho, são percebidas pelos médicos como controladoras; c) frente a tais estratégias, os médicos procuram preservar seus espaços de autonomia desenvolvendo contraestratégias que ofereçam resistência à sua implantação.

O hospital examinado foi escolhido para este estudo por ter sido submetido a diversos processos de avaliação que, em graus diferentes, induziram políticas racionalizadoras da vida do hospital, destacando-se, em particular, seu contrato de gestão junto à Secretaria Estadual de Saúde, o processo de acreditação hospitalar, sendo certificado em nível III de excelência em gestão na metodologia ONA (Organização Nacional de Acreditação), e sua contratualização como Hospital de Ensino pelos Ministérios da Saúde e da Educação. Todos esses processos de avaliação/certificação/contratualização têm em comum o fato de, em algum grau, almejarem maiores visibilidade, homogeneização e controle do ato médico.

\section{Metodologia}

Para responder às perguntas deste estudo, optou-se por uma pesquisa social, isto é, investigação que trata do ser humano em sociedade, de suas relações e instituições, de sua história e de sua produção simbólica, que toma a dimensão da experiência do indivíduo como objeto de estudo (MINAYO, 2007), mais especificamente um estudo de caso, nos moldes apontados por Yin (2005). Para Minayo (2007, P. 204):

o que torna o trabalho interacional um instrumento privilegiado de coleta de informações para as ciências sociais é a possibilidade de a fala ser reveladora de condições estruturais, de sistemas de valores, normas e símbolos e, ao mesmo tempo, ter a magia de transmitir, através de um porta-voz, as representações de grupos determinados, em condições históricas, socioeconômicas e culturais específicas.

Entretanto, é possível se perguntar: em que medida a fala dos médicos entrevistados é representativa dos demais médicos que trabalham no hospital estudado ou até mesmo dos médicos em geral? Para responder a essa pergunta, parte-se do pressuposto de que a fala, por seu caráter histórico e social, constitui-se como fenômeno ideológico por excelência e campo de expressão das relações e dos conflitos. É por meio dela que se confrontam valores sociais contraditórios, sendo que

cada época e cada grupo social têm seu repertório de formas de discurso, marcado pelas relações de produção e pela estrutura sociopolítica. (BAKHTIN, 1986 APUD MINAYO, 2007, P. 205).

Neste caso, pode-se considerar que os entrevistados são médicos que, submetidos a condições semelhantes de trabalho e experiência organizacional, apresentarão, através da fala, representações de seu grupo de pertença. Dessa forma, seus discursos tendem a reproduzir sistemas de disposições semelhantes, mas sem perder sua singularidade, através do que Bourdieu (1973) chamou de um tipo de harmonização ou cristalização objetiva de práticas e obras que se repetem em usos e costumes.

Além disso, por ser expressão de relações e conflitos, a busca das tensões existentes nos discursos ou, em alguns momentos, a ausência delas serviu ao estudo como estratégia para a identificação das relações existentes entre as representações de prática 
e a situação profissional concreta, em que incidem as políticas racionalizadoras da gestão hospitalar.

Para a coleta de dados, foram usadas as seguintes técnicas: a) análise documental - em particular, a leitura de todos os documentos adotados pela direção do hospital nos processos de acreditação e contratualização externa do hospital; b) entrevistas semiestruturadas com médicos - questões direcionadas ao processo de trabalho desses profissionais, em uma abordagem reflexiva, sendo possível apreender como os médicos escutados vivenciam e dão sentido às práticas racionalizadoras da gestão.

Os médicos entrevistados foram identificados por sorteio entre aqueles que cumprissem os critérios de inclusão: possuir vínculo de, no mínimo, dois anos no hospital, dedicação mínima de 24 horas semanais e atuar diretamente na assistência em um dos seguintes serviços hospitalares: clínica médica, pediatria, urgência e emergência, terapia intensiva de adultos e cirurgia geral, totalizando seis médicos entrevistados, um de cada serviço.

Para a análise do material, foram realizadas repetidas leituras das entrevistas, buscando-se encontrar nelas blocos de sentidos' que permitissem a caracterização de certo 'horizonte compartilhado' pelos médicos do hospital, sempre pautado pela indagação central da pesquisa: afinal, como eles vivem e dão sentidos para os fortes movimentos de racionalização adotados pela direção do hospital?

A aprovação pelo Comitê de Ética em Pesquisa deu-se através do protocolo CEP 0214/09.

\section{Resultados}

A análise documental do estudo utilizou-se dos documentos adotados pela direção do hospital nos processos de acreditação e contratualização como hospital de ensino e teve como objetivo 'evidenciar estratégias gerenciais com potencial de intervir na prática dos médicos'. Entre elas: auditoria de prontuários; avaliação da qualidade dos atestados de óbito e relatórios de alta; análise de eventos sentinela (óbito materno, anoxia neonatal, tocotrauma, surto por germe multirresistente, cirurgia em membro/paciente errado, cancelamento de cirurgia com consequências ao paciente, erros de medicação, broncoaspiração etc.); padronização de antibióticos com auditoria da prescrição pelo Serviço de Controle de Infecção Hospitalar e necessidade de autorização prévia para dispensação dos antibióticos de amplo espectro pela farmácia; implantação de protocolos de profilaxia cirúrgica institucional; controle de interações medicamentosas pela farmácia e intervenção sobre a prescrição no caso de interações graves; implantação de protocolo de sedação institucional; implantação de termo de consentimento informando sobre procedimentos anestésico e cirúrgico e exames; implantação dos manuais de protocolos assistenciais a serem seguidos pelos médicos contratados; presença de cartão de ponto para todos os profissionais, incluindo médicos; regulação do acesso baseado em indicadores gerenciais, como taxa de ocupação, média de permanência, ociosidade de ambulatórios, ociosidade do Centro Cirúrgico e Centro Cirúrgico Ambulatorial etc. (exemplo: diminuição de leitos de UTI neonatal e semi-intensivo baseada na taxa de ocupação com redimensionamento de equipe médica).

A análise documental, por si só, dá uma dimensão da complexidade e da amplitude das estratégias normalizadoras adotadas pela direção. Mesmo reconhecendo que parte dessas estratégias é dependente da ação articulada da equipe de saúde, é possível dizer que, em todas elas, há um importante elemento da prática médica sendo avaliado, disciplinarizado, controlado e/ou regulamentado pela direção do hospital.

As entrevistas permitiram identificar 
tensões e convergências entre essa racionalização da vida hospitalar e os sentidos que os médicos dão para seu trabalho indicando, tal como sugerido em debates recentes, o quanto a autonomia médica e o gerencialismo não devem ser conceituados necessariamente como contrários.

Pode-se observar que, de uma forma geral, os médicos referem gostar de trabalhar no hospital, sempre a partir da comparação com outros hospitais públicos em que trabalham ou já trabalharam. Nessa avaliação positiva, em comparação com outras instituições hospitalares, atribuem valor a quatro fatores principais: possibilidade de desenvolverem uma 'medicina de qualidade', com bons resultados para o paciente; possibilidade de continuar aprendendo e se aperfeiçoando; possibilidade de estabelecer uma relação menos conflituosa com a equipe, quando comparam com outros hospitais ('estar entre amigos'); reconhecerem uma menor pressão por atendimento, pelo fato de o hospital possuir emergência referenciada.

Nota-se que, quando falam em qualidade da assistência prestada, atribuem o resultado a três fatores principais: a coesão e a qualidade da equipe, a organização ou o funcionamento do hospital e a estrutura hospitalar.

Quando falam em qualidade da equipe como fator de influência na qualidade da assistência prestada, referem-se, em particular, aos médicos, em geral, colegas da mesma universidade responsável pela gestão do hospital. Vale destacar que quatro dos seis entrevistados sorteados são formados e realizaram residência médica naquela universidade, predominância essa que pôde ser confirmada nas entrevistas. Por exemplo:

Ah, porque eu me formei na Universidade $X$, fiz quatro anos de especialização lá, já convivia, mais ou menos, com todo esse pessoal que trabalha aqui. Isso aqui foi meio que um..., um hospital que..., como foi a Universidade $X$ que foi a responsável por gerenciar, naturalmente, pessoas da Universidade $X$ foram, tiveram acho que $a$ preferência na escolha, e eu estava entre essas pessoas aí no grupo da cirurgia. Ainda trabalho na cirurgia da Universidade $X$, sou plantonista lá.

A vida das organizações é entendida como o resultado de uma vasta e variada gama de negociações entre uma grande diversidade de profissionais, com diferentes tipos de formação e socialização, com diferentes posições hierárquicas e com diferentes localizações na divisão do trabalho médico (STRAUSS, 1963) e na disputa pela distribuição dos recursos e pelo poder (DUSSAULT, 1992). No hospital estudado, o fato de a grande maioria dos médicos ser egressa da mesma escola médica funciona como um verdadeiro 'cimento simbólico', que fornece coesão entre eles, não apenas facilitando o processo de negociação, mas, principalmente, definindo as regras com que esses profissionais vão operar na instituição, criando um universo autônomo de movimentação desses profissionais, independentemente das regras formais da direção.

Esse 'cimento simbólico' cria um território seguro e conhecido para o médico. O hospital em estudo, apesar de ser completamente independente do Hospital Universitário, inclusive localizado em outro município, é visto, pelos médicos, como sua 'extensão', elemento valorizado como tendo impacto positivo na qualidade da assistência prestada, conforme é abordado a seguir.

Com relação ao funcionamento do hospital, observa-se que os médicos valorizam as regras organizacionais, em particular, os protocolos e as normas que regulamentam a relação entre os serviços assistenciais (pedidos de interconsulta, relação entre as unidades no trânsito de pacientes etc.) e entre estes e os serviços de apoio (agilidade nos pedidos de exames laboratoriais, de imagem etc.), apesar dos conflitos inerentes a essas relações, o que pode ser visto como uma convergência entre os movimentos de 
funcionalização e racionalização da vida hospitalar, e o que os médicos consideram como as condições para a boa prática profissional.

A expressão maior dessa valorização é a ‘organização’ ser eleita como uma das coisas que os médicos mais gostam no hospital, no sentido de 'ser organizado', 'ter ordem', e as práticas racionalizadoras da gestão serem percebidas como um 'mal necessário', como se um controle maior por parte da direção também representasse uma 'moralização' em comparação com outras, onde as relações parecem ser mais degradadas.

Então, eu tenho um pouco de compulsão, assim, de organizar as coisas, principalmente com agenda, para não perder nenhum compromisso em casa, deixar as coisas bem organizadas. Então, quanto a isso, do ponto de vista da cobrança, é para mim uma coisa normal. Acho normal e necessária. Eu vejo que alguns hospitais lá de São Paulo, que eu considero, sabe, um insucesso total, um fracasso se for avaliar do ponto de vista geral, de atendimento, recuperação do paciente. E lá falta exatamente isso: hospital do Estado. Só tinha funcionário publico, não tinha mecanismo punitivo, não tinha mecanismo de cobrança, de horário, entendeu? Então, assim, resumindo, acho que é um mal necessário.

Quando o médico, no hospital estudado, valoriza sua forma de funcionar (a 'organização') e reconhece as práticas racionalizadoras da gestão como um 'mal necessário' ou como regras que devem ser respeitadas e seguidas, pode-se dizer que existe uma identificação do profissional com a ordem estabelecida, que o faz preferir trabalhar nesse hospital em comparação com outros. Assim, a valorização da 'organização' do hospital pelo médico pode ser considerada como um 'alinhamento moral' dos médicos às estratégias racionalizadoras adotadas pela direção do hospital, em particular, quando vai sendo estabelecido, de modo crescente, não só o que é 'certo' e o que é ‘errado' na vida hospitalar, como vai criando os mecanismos explícitos de controle e cobrança das práticas, aceitos ou valorizados pelos profissionais: uma 'moralização’ da vida organizacional.

Por aceitarem essa 'moral', não fazem uma crítica estruturada à direção, por exemplo, com relação a seus mecanismos de controle, mesmo que, no limite, isso implique algum cerceamento de sua autonomia.

Além do importante componente 'moral', a análise do material empírico evidencia que parte dessas práticas vem revestida de (e legitimada por) um forte componente científico, ambos valores presentes nos médicos e de fácil identificação, o que permite sua internalização, apropriação e reconfiguração. Fica claro, dessa forma, que existe algum grau de convergência entre aquilo que os médicos e a direção avaliam como qualidade da assistência. Isso não significa que não existam desacordos ou propósitos discrepantes, mas há um claro reconhecimento dos médicos como sendo 'legítimas' as práticas racionalizadoras da gestão.

A divergência, sim, essa explicitamente apontada por todos os entrevistados, refere-se especificamente aos salários considerados injustos pelo trabalho realizado e, como consequência, o marcado sentimento do que seria a não valorização e o não reconhecimento do trabalho médico pela direção do hospital. Está aí o fosso, que aparentemente se alarga, pelo menos no momento da realização do campo, entre direção e médicos. Trata-se de um impressionante elemento (negativo) do 'sentido de pertença' existente entre os médicos, muito mais expressivo do que qualquer formulação bem elaborada sobre os constrangimentos que os inegáveis elementos racionalizadores presentes na vida organizacional possam apresentar em sua autonomia profissional, como se imaginava existir no início da pesquisa.

Vale ressaltar, ainda, que cinco dos seis médicos entrevistados são profissionais assalariados que não possuem consultório privado. Nesse caso, pode-se dizer que 
estamos diante de um profissional médico que se aproxima de uma situação de institucionalização plena, no polo oposto do médico liberal. O 'médico plenamente institucionalizado' é o profissional totalmente assalariado, que cumpre horário, submetido ao uso de protocolos, ao monitoramento de indicadores, ao controle do acesso e do fluxo de pacientes, em que o paciente é cada vez mais 'do hospital' e não mais 'do médico'. Ainda assim, o médico tenta preservar algum grau de autonomia na condução do caso, no cuidado direto com o paciente, tentando articular, dentro do hospital e no sistema de saúde, o cuidado que avalia como sendo necessário para os seus pacientes.

Assim, é possível perceber uma clara tensão no exercício profissional do médico no hospital, que poderia ser assim caracterizada: se, por um lado, ele está 'hiperinstitucionalizado' e aparentemente se identifica com a gestão do hospital, de algum modo 'aceitando' seus crescentes mecanismos de controle, por outro, e apesar de tudo, ele ainda se move de acordo com seu referencial profissional, centrado em sua autonomia técnica na condução do caso, aparentemente potencializado pelo forte 'sentido de pertença' encontrado no hospital, como o estudo apontou.

Pode-se afirmar que são duas racionalidades funcionando simultaneamente $\mathrm{e}$ que convivem em negociação permanente: uma administrativa, que interfere e coloniza a prática do médico, e outra médica, que disputa e limita o controle da direção do hospital. Como sugerido por Noordegraaf (2007, 2011) ou Correia (2014), essas racionalidades que traduzem os valores e ideais do gerencialismo e do profissionalismo tanto estão em conflito como se compatibilizam. O estudo mostra como os valores e ideais dos médicos de autonomia no exercício da profissão, uma característica constitutiva de seu trabalho, parecem se compor dos marcantes mecanismos de controle adotados pela direção do hospital, aparentemente limitadores de sua autonomia. Isso indica como instrumentos gestionários são internalizados, apropriados e reconfigurados pelos médicos, no sentido de que, em graus variáveis, podem tornar parte integrante da racionalidade médica.

O estudo não evidenciou nada que pudesse ser identificado como contraestratégias de resistência aos processos racionalizadores, se aquelas forem definidas como atividades 'conscientes', 'ativas e articuladas' que resultem em algum modo de boicote, de enfrentamento com relação ao 'cerco que se vai fechando'. Como exemplos de estratégias ativas, poderiam ser apontados: negativa de preenchimento de determinados impressos, recusa de se submeter aos critérios de admissão e alta dos pacientes, resistência em seguir protocolos adotados e aceitar ingerências sobre o tempo de permanência do paciente hospitalizado, não reconhecimento de novos papéis de outros profissionais que interferem de alguma maneira no seu núcleo de autonomia, como a classificação de riscos de pacientes na urgência etc. Pelo menos não foram encontradas referências na escuta dos médicos, em nenhum momento, a tais movimentos, o que é consentâneo com conclusões de outros estudos europeus (CORREIA, 2012).

Mesmo considerando que tal 'silêncio' possa ser parte de uma atitude de 'ocultamento', consciente ou não, perante a pesquisadora, que já participou da direção do hospital, o que se percebe com mais evidência é o quanto a 'resistência' dos médicos às medidas racionalizadoras se faz em ato, na realização do seu trabalho, na criação de redes informais de contatos e conhecimentos, e que vai produzindo fluxos, modos de funcionamento do hospital, de produção do cuidado, que extravasam a racionalidade, o formalismo e a previsibilidade desejados pela direção. É na sua prática cotidiana, na responsabilização que assumem pelos pacientes, nas articulações que fazem com seus pares, dentro e fora do hospital, atuando segundo seus critérios e valores, que os médicos 'resistem' à construção de 
um mundo hospitalar totalmente formatado, previsível e controlável. Os médicos resistem não por meio de 'contraestratégias' ativas e conscientes, como se tomou como pressuposto no início do estudo, mas por sua movimentação cotidiana na produção do cuidado e na articulação incessante que fazem com os outros atores, aí incluídas as demais categorias profissionais, os pacientes e seus familiares. É através da realização de pequenas 'contravenções', da quebra de regras, da flexibilização das normas que o médico resiste ao projeto de um mundo totalmente racionalizado e previsível. É isso que ainda 'bagunça' a pretensão de racionalidade plena.

\section{Conclusões}

A aparente coerência e a pretensa articulação interna das políticas racionalizadoras da vida hospitalar, presentes no discurso dos dirigentes, não foram reproduzidas dessa forma pelos médicos entrevistados. Falando a partir de seu mundo do trabalho e da complexa trama de relações institucionais que vão construindo para produzir seu cotidiano, pautados pelo sentido ético que imprimem à sua prática profissional, pelo forte 'sentido de pertença' que existe no hospital, os médicos produzem outro discurso, mais fragmentado, elaborado com outros elementos, guiado por outras lógicas e que, afinal, resulta em algo que não é simples 'espelho' ou reflexo do que a direção pretende. Os médicos produzem sentidos para seu cotidiano que escapam a qualquer pretensão mais 'macro' e mais global do discurso institucional, o qual os imagina agindo de acordo com sua lógica.

$\mathrm{Na}$ verdade, os médicos até percebem que há evidentes e crescentes medidas de controle e acompanhamento, de construção de regras a serem cumpridas, de interdições mais ou menos veladas com relação às suas práticas, mas, por um paradoxal efeito, e o estudo mostra bem isso, não só parecem se sentir imunes a tais movimentos como também demonstram certa convergência e identificação que permitem sua internalização, apropriação e reconfiguração.

A pesquisa mostra como, em alguma medida, as práticas racionalizadoras dirigidas à 'organização' da vida no hospital são vistas como uma bem-vinda 'moralização' da vida organizacional, de modo que a definição clara do que é 'bom' e o que é 'ruim', do que é 'certo' e do que é 'errado' parece facilitar ou promover um ambiente de trabalho mais favorável, com regras claras e cumpridas por todos, resultando em algo avaliado pelos médicos como positivo para a sua prática profissional. Diante da reconhecida crise dos hospitais, que tem resultado em denunciada degradação do cuidado, trabalhar em um hospital que adota e segue rigorosas regras de funcionamento, que atingem a todos, sem exceção, acaba sendo a face mais visível da racionalização da vida hospitalar e um fato positivo, como sugerido por Noordegraaf (2011).

Ao mesmo tempo, da perspectiva pessoal, os médicos seguem pairando sobre tais regras, reafirmando sua autonomia como 'símbolo mítico de seu ideal de prática'. Algo como:

as regras existem, mas posso sempre de algum modo contorná-las, flexibilizá-las, legitimado por uma autoridade técnica e por uma responsabilidade social que me autorizam a tanto (e que ainda não me foi retirada...).

Nesse sentido, a aparente relação de alternância de dominância entre o poder médico e o poder administrativo, indicando equilíbrio entre as duas racionalidades, também poderia ser hibridizada ao pensarmos que a 'racionalidade administrativa' é, em boa medida, submetida e construída a partir dos cânones da racionalidade científica. Daí o seu não estranhamento e sua identificação pelos médicos. Tal afirmação, entretanto, 
demanda estudos mais cuidadosos e direcionados a um melhor equacionamento dessa relação.

Trata-se, portanto, e como reflexão que finaliza essa investigação, de tentar imaginar o que resultará de tais movimentos identificados de forma tão marcante no hospital: por um lado, uma lógica que pretende dar

\section{Referências}

BOURDIEU, P. Le métier de sociologue. Paris: MoutonBordas, 1973.

CARAPINHEIRO, G. Saberes e poderes no hospital: uma sociologia dos serviços hospitalares. 3. ed. Porto: Afrontamento, 1998.

CORREIA, T. Medicina: o agir numa saúde em mudança. 1. ed. Lisboa: Mundos Sociais, 2012.

CORREIA, T. Connecting medical professionalism and large bureaucracies in the changing hospital governance. The European Journal of Public Health, Oxford, v. 24, supl. 2, p. 181-181, 2014.

DUSSAULT, G. A gestão dos serviços públicos de saúde: características e exigências. Revista de Administração Pública, Rio de Janeiro, v. 26, n. 2, p. 08-19, 1992.

FREIDSON, E. Professionalism: the third logic. Oxford: Polity Press, 2001.

MEYER, P. A irresponsabilidade médica. São Paulo: Editora Unesp, 1999.

MINAYO, M. C. S. O desafio do conhecimento: Pesquisa Qualitativa em Saúde. 10. ed. São Paulo: Hucitec, 2007.

NOORDEGRAAF, M. From "pure" to "hybrid"

professionalism: Present-day professionalism in ambiguous public domains. Administration Society,

New York, n. 39, p. 761-785, 2007. a máxima homogeneidade, visibilidade e previsibilidade para a vida organizacional; por outro, aquela ainda movida pela ação humana, pelos fluxos de encontros que se dão no e constituem o hospital, por aquilo que sempre fugirá ao controle, ao instituído, almejando a atualização permanente da potência da criação humana.

\footnotetext{
Risky Business: how professionals and professional fields (must) deal with organizational issues. Organization Studies, Bruxelas, v. 32, n. 10, p. 1349-1371, 2011.
}

PAULA, A. P. P. Administração pública brasileira entre o gerencialismo e a gestão social. $R A E$, São Paulo, v. 45, n. 1, p. 36-49, jan./mar. 2005.

SCHRAIBER, L. B. O médico e seu trabalho: limites da liberdade. São Paulo: Hucitec, 2. ed., 1993.

$$
\text { O médico e suas interações: a crise dos vínculos }
$$
de confiança. 1. ed. São Paulo: Aderaldo \& Rothschield, 2008.

STRAUSS, A. et al. The Hospital and Its Negotiated Order. In: Friedson, E., The Hospital in Modern Society. Nova York: The Free Press, 1963.

VIEIRA, M. M. F.; CARVALHO, C. P. C. Qualidade e objetivos: implicações teóricas e metodológicas para a análise das organizações. In: VIEIRA, M. M. F.; OLIVEIRA, L. M. B. (Org.). Administração Contemporânea: perspectivas estratégicas. Rio de Janeiro: Atlas, 1999.

YIN, R. K. Estudo de Caso: planejamento e métodos. 3. ed. Porto Alegre: Bookman, 2005.

\footnotetext{
Recebido para publicação em maio de 2015

Versão final em janeiro de 2016

Conflito de interesses: inexistente
}

Suporte financeiro: não houve 